The Egyptian Journal of Hospital Medicine (January 2019) Vol. 74 (4), Page 782-788

\title{
Evaluation of the Effect of Diabetes Mellitus on Corneal Biomechanics
}

\author{
Abd Elmagid Mohamed Tag Eldin, Abdulmoez Haddad Ahmed, Amr Khalil Abdelmonem* \\ Ophthalmology department, Faculty of Medicine, Al-Azhar University
}

*Corresponding author: Amr Khalil Abdelmonem, E-Mail: AmrKhalilAbdelmonem@gmail.com, Mobile: 01002877071

\begin{abstract}
Background: the cornea exhibits viscoelastic properties, which give it the quality of hysteresis. Corneal hysteresis is an important indicator of the biomechanical properties of the cornea.

Aim: to compare the biomechanical properties of the cornea in patients having diabetes mellitus and age matched normal individuals as regards to corneal hysteresis $(\mathrm{CH})$, corneal resistance factor $(\mathrm{CRF})$, Corneal compensated IOP (IOPcc) and Goldman- correlated IOP (IOPg).
\end{abstract}

Patients and Methods: A total of 200 eyes of 100 patients were enrolled in our study. Patients were selected from Ophthalmology outpatient clinics in Minia Health Insurance Hospital - Ophthalmology department. The type of our study is a case-control one. Patients were divided into two equal groups:

Group A: included 50 patients (100 eyes) of age matched normal individuals.

Group B: included 50 patients (100 eyes) having type 2 diabetes mellitus.

Results: mean $\mathrm{CH}$ in control group was $9.8 \pm 1.3 \mathrm{~mm} \mathrm{Hg}$ in comparison to mean $\mathrm{CH}$ in diabetic group which was $11.9 \pm 1.4 \mathrm{~mm} \mathrm{Hg}$, which was statistically significantly higher in diabetic patients when compared to control group, $(P$ value $=0 .<001)$.

Conclusion: the corneal biomechanics in diabetic group are significantly higher compared with those of the control group.

Keywords: Cornea, corneal hysteresis, corneal resistance factor, intra-ocular pressure, diabetes mellitus, corneal compensated intra-ocular pressure, Goldman correlated intra-ocular pressue.

\section{Introduction}

Biomechanics of the cornea affect its functional responses and greatly impact vision. The physical composition of the cornea gives it a viscoelastic property which means that it exhibits elements of both elasticity and viscosity $(\mathbf{1 , 2})$.

Elasticity refers to the ability of a substance to deform reversibly under stress. Viscous materials, on the other hand, flow when an external shear force is applied and do not regain their original shape when the force is removed. Viscoelastic materials exhibit characteristics of both viscosity and elasticity, resulting in energy dissipation when stress is applied. The energy lost in this dissipation process is called hysteresis $(\mathrm{CH}){ }^{(3)}$.

The Ocular Response Analyzer (ORA) (Reichert Inc., Depew, New York), described by Luce ${ }^{(4)}$, is the only commercially available medical device capable of measuring corneal biomechanics. In vivo Studies have shown that $\mathrm{CH}$ is altered in various disease states. Measurement of $\mathrm{CH}$ also provides a more complete characterization of the contribution of corneal resistance to intraocular pressure (IOP) measurements than central corneal thickness $(\mathrm{CCT})^{(5)}$.

The ORA uses a puff of air to deflect the cornea while an infrared beam tracks changes in the shape of the anterior cornea during inward and outward deviation. Analysis of the parameters produced by the infrared waveform signal allows the calculation of several useful values. Corneal hysteresis $(\mathrm{CH})$ is calculated as the difference in air pressures between force-in applanation (P1) and force-out applanation (P2), or $(\mathrm{P} 1-\mathrm{P} 2)$. However, corneal hysteresis values can be produced by various combinations of corneal thickness, rigidity, intraocular pressure, and hydration. Corneal resistance factor is another measurement provided by ORA ${ }^{(4)}$.

Diabetes leads to complications in almost all ocular structures, diabetes significantly impacts the morphological, metabolic, physiological and clinical properties of the cornea (6).

\section{Aim of the Work:}


To compare the biomechanical properties of the cornea in patients having diabetes mellitus and age matched normal individuals as regards to corneal hysteresis $(\mathrm{CH})$, corneal resistance factor (CRF), Corneal compensated IOP (IOPcc) and Goldman- correlated IOP (IOPg).

\section{Patients and Methods}

A total of 200 eyes of 100 patients were enrolled in our study. Patients were selected from Ophthalmology outpatient clinics of Health Insurance Hospital. The type of our study is a case-control one. Patients were divided into two equal groups:

Group A: this included 100 eyes of age matched normal individuals.

Group B: this included 100 eyes of patients having type 2 diabetes mellitus.

\section{- Inclusion criteria:}

1. Patients aged less than 50 years old of either gender.

2. In group A: normal population as control group coming for outpatient clinic for routine ophthalmological examination.

3. In group B: patients having type 2 Diabetes Mellitus for at least five year duration.

4. Patients with stable refractive error.

\section{- Exclusion criteria:}

1. Patients having history of ocular surgery.

2. Patients having history of refractive surgery.

3. Patients having systemic diseases other than Diabetes Mellitus that affects corneal biomechanics.

4. Patient having collagen diseases as Rheumatoid or Lupus Erythromatous.

5. Patient having corneal diseases or dystrophy.

6. Patients having keratoconus.

7. Patients having glaucoma or glaucoma suspects.

8. Patients having unstable refractive errors.

9. Central corneal thickness $<510$ um or $>600$ um.

\section{- Patient's evaluation:}

We planned to evaluate the effect of DiabetesMellitus on the corneal biomechanics.

All patients underwent:

A. A Full history taking with special emphasis on:

1- Age.

2- Duration of diabetes.

3- Diabetic control status.

4- History of previous ocular surgeries.

B. Complete ophthalmic examination in the form of:

1- Pupillary reaction.

2- Visual Acuity Measurement: Uncorrected visual acuity (UCVA) and best corrected visual acuity (BCVA) were measured using Snellen's chart.

3- Anterior segment examination by slit lamp examination.

4- Fundus examination using +20 D lens (funduscopy) and $+90 \mathrm{D}$ lens (bimicroscopy) after pupillary dilatation with tropicamide $1 \%$ eye drops.

C. Investigations were done in the form of:

1. ORA to measure $\mathrm{CH}, \mathrm{CRF}, \mathrm{IOPg}$ and IOPcc.

2. Measurement of central corneal thickness (CCT, Pachymetry) by Pentacam (Pentacam ${ }^{\circledR}$, Oculus).

D. Investigations done to diagnose diabetic patients:

1 - Fasting blood glucose (FBG).

2- Random blood glucose (RBG).

3- Glycated hemoglobin (Hb A1C).

\section{Ethical issues:}

The hospital Ethics Committee approved the study.

\section{Consent Process:}

The population sample under study was instructed about research protocol and informed consent is granted from each participant before randomization.

Data analysis:

The collected data of normal and diabetic patients were tabulated in spreadsheets using Microsoft Office Excel 2007 (Microsoft Corporation, USA). The coded data were 
arranged for use in SPSS Statistical Computer Package (SPSS 2011, version 20, IBM Corporation, USA). The first step in statistical analysis was to conduct descriptive statistics on the file containing the collected data of the 100 patients. Descriptive data were summarized and presented herein for numerical data as the mean \pm Standard deviation (SD).

\section{Results}

\section{The ORA measurements:}

1. Corneal hysteresis $(\mathrm{CH})$ :

The $\mathrm{CH}$ of the study groups ranged from 6.9 to $15.5 \mathrm{mmHg}$ with an average of $11.7 \pm 1.8$ $\mathrm{mmHg}$ for the control group (group A) while It ranged from 9.6 to $17.7 \mathrm{~mm} \mathrm{Hg}$, with an average $11.9 \pm 1.4 \mathrm{~mm} \mathrm{Hg}$ for the diabetic group (group B). The difference between the two groups was statistically highly significant $(p$ - value $=$ $<0.001)$.

Table 1: The corneal hysteresis of the study group in $\mathrm{mm} \mathrm{Hg}$

\begin{tabular}{|l|l|l|l|l||}
\hline & $\begin{array}{l}\text { Total } \\
\text { N=200 eye }\end{array}$ & $\begin{array}{c}\text { Group A } \\
\text { (control group) } \\
\mathbf{N = 1 0 0}\end{array}$ & $\begin{array}{c}\text { Group B } \\
\text { (diabetic group) } \\
\mathbf{N = 1 0 0}\end{array}$ & P-value \\
\hline Corneal hysteresis & $6.9-17.7$ & $6.9-15.5$ & $9.6-17.7$ & $<\mathbf{0 . 0 0 1}$ \\
& $11.7 \pm 1.8$ & $9.8 \pm 1.3$ & $11.9 \pm 1.4$ & \\
\hline
\end{tabular}

A correlation was done between the $\mathrm{CH}$ and the average of duration of diabetes for the diabetic group (group B). The correlation was found to be a weak positive linear correlation $(\boldsymbol{r}$ value $=\mathbf{0 . 2 7 3})(p$ value $=\mathbf{0 . 0 8 9})$.

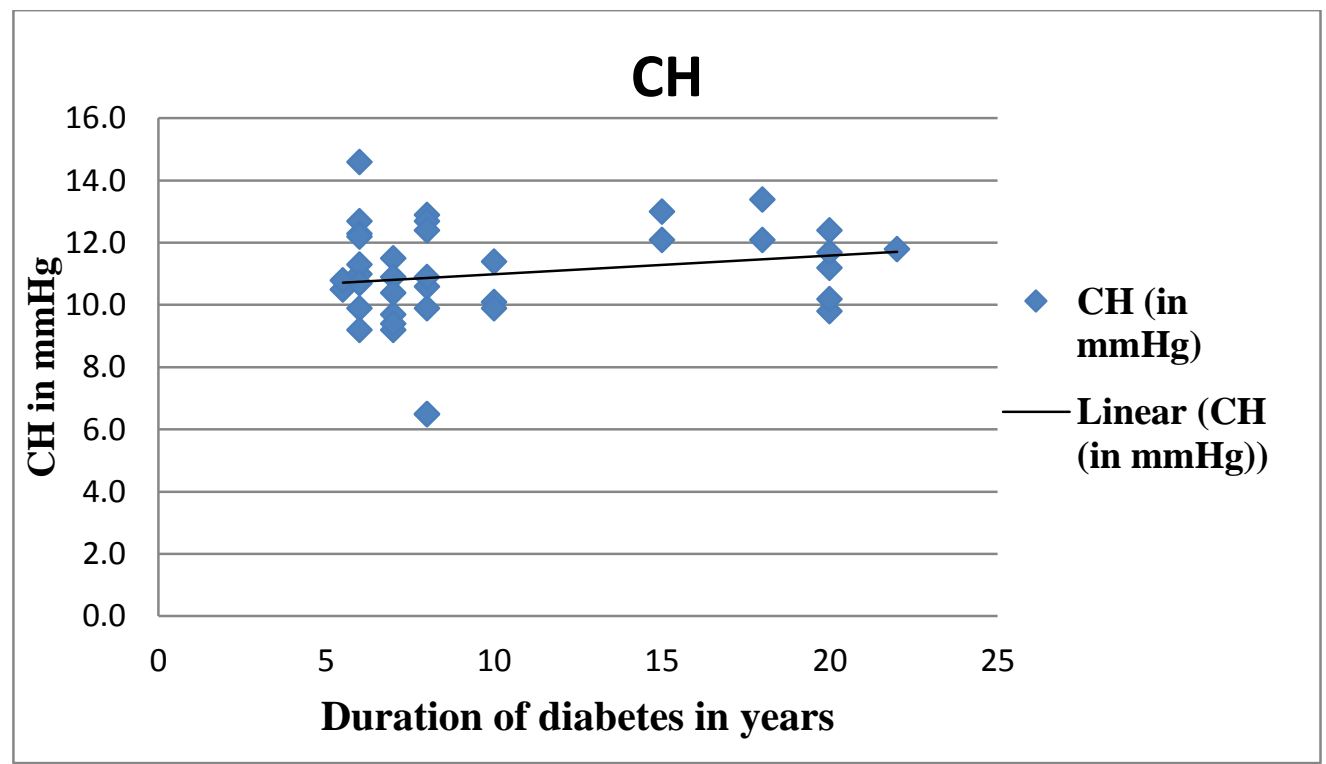

Figure 1: A scatter plot showing the weak positive linear correlation between $\mathrm{CH}$ and the average duration of diabetes $(\boldsymbol{r}$ value $=0.273)$.

We also have correlated $\mathrm{CH}$ to the average level of HBA1c in the control group and it showed no correlation $(\boldsymbol{r}$ value $=\mathbf{0 . 0 0 5})$. 


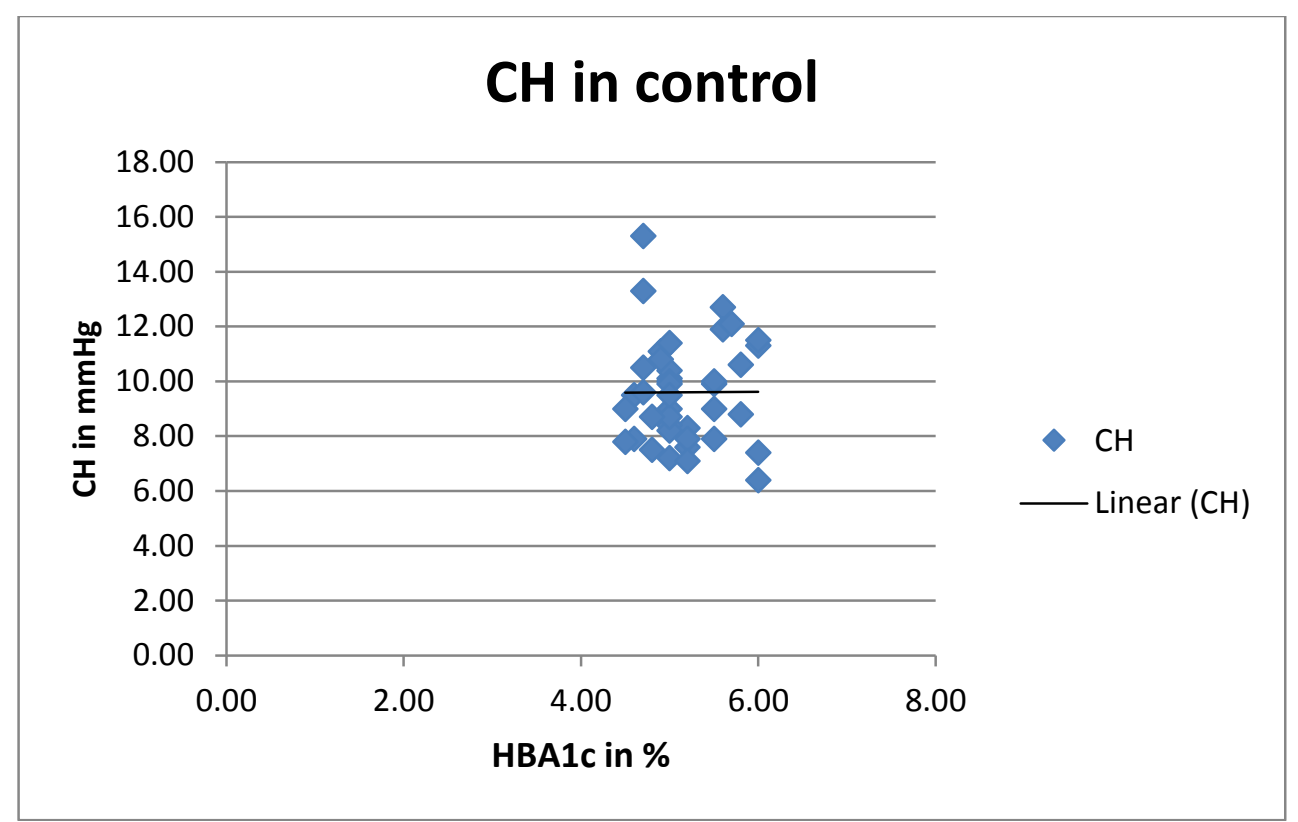

Figure 2: A scatter plot showing no correlation between $\mathrm{CH}$ and the average HBA1c in control group $(\boldsymbol{r}$ value $=0.005$ ).

When correlating the $\mathrm{CH}$ to the average level of $\mathrm{HBA1C}$ in the diabetic patients in the diabetic group (group B), we found it a weak positive linear correlation $(\boldsymbol{r}$ value $=\mathbf{0 . 1 2 9})(\boldsymbol{p}$ value $=\mathbf{0 . 4 2 7})$.

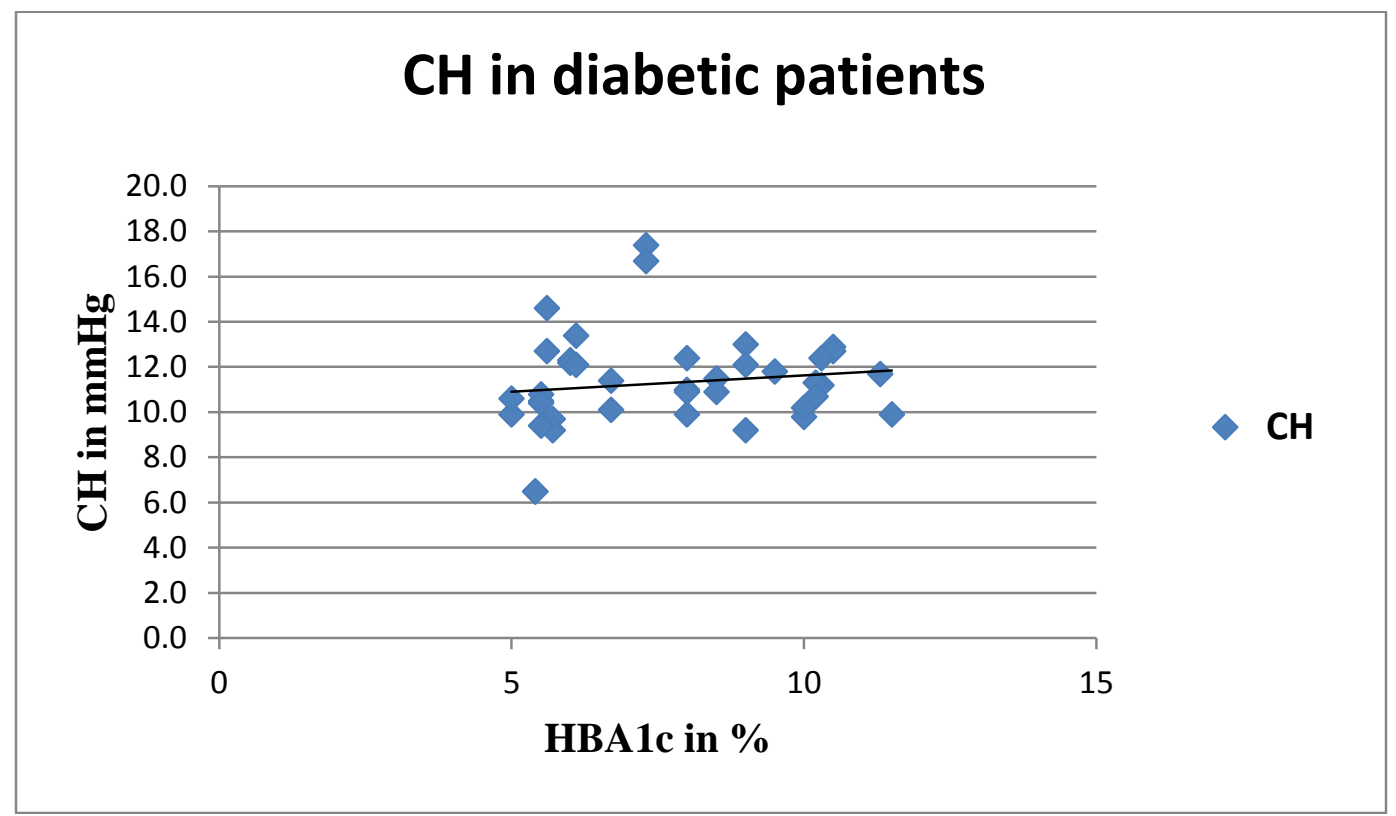

Figure 3: A scatter plot showing the weak positive linear correlation between $\mathrm{CH}$ and HBA1c in diabetic group of the 40 patients $(\boldsymbol{r}$ value $=0.129)(\boldsymbol{p}$ value $=0.427)$.

\section{Corneal resistance factor $(\mathrm{CRF})$ :}

The CRF of the study groups ranged from 6.6 to $14 \mathrm{~mm} \mathrm{Hg}$, with an average of $9.41 \pm 1.5 \mathrm{mmHg}$ for control group (group A) and ranged from 8.9 to $16.4 \mathrm{mmHg}$, with an average of $12.4 \pm 1.7 \mathrm{~mm} \mathrm{Hg}$ for the diabetic group (group B). The difference between the two groups was statistically highly significant $(p$ - value $=0.001)$. 
Evaluation of the Effect of Diabetes Mellitus on Corneal Biomechanics

Table 2: The corneal resistance factor of the study groups in $\mathrm{mm} \mathrm{Hg}$

\begin{tabular}{|c|c|c|c|c|}
\hline & $\begin{array}{l}\text { Total } \\
\mathrm{N}=200 \text { eye }\end{array}$ & $\begin{array}{c}\text { Group A } \\
\text { (control group) } \\
N=100\end{array}$ & $\begin{array}{c}\text { Group B } \\
\text { (diabetic group) } \\
N=100\end{array}$ & P-value \\
\hline $\begin{array}{ll}\text { Corneal } & \text { resistant } \\
\text { factor } & \end{array}$ & $\begin{array}{l}6.8-16.4 \\
11.0 \pm 2.1\end{array}$ & $\begin{array}{l}6.6-14 \\
9.41 \pm 1.5\end{array}$ & $\begin{array}{l}8.9-16.4 \\
12.4 \pm 1.7\end{array}$ & 0.001 \\
\hline
\end{tabular}

When we correlated CRF to the average duration of diabetes mellitus in the diabetic group (group B), the correlation was found to be a weak positive linear one $(\boldsymbol{r}$ value $=\mathbf{0 . 2 3 7})(\boldsymbol{p}$ value $=\mathbf{0 . 1 4 1})$.

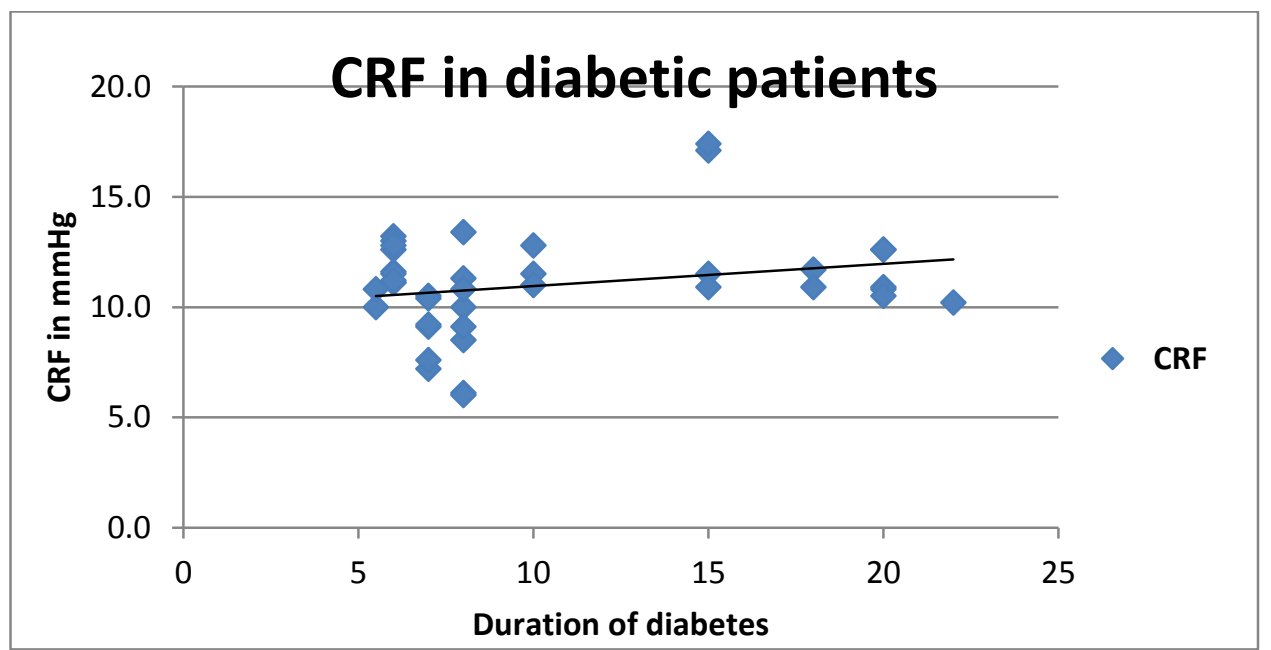

Figure 4: Scatter plot showing weak positive linear correlation between CRF and duration of diabetes mellitus, $(\boldsymbol{r}$ value $=0.237)(\boldsymbol{p}$ value $=0.141)$.

The correlation done between the CRF and the average level of HBA1c in the control group patients (group A) showed very weak negative linear correlation, $(\boldsymbol{r}$ value $\mathbf{=} \mathbf{- 0 . 0 9 2}$ ).

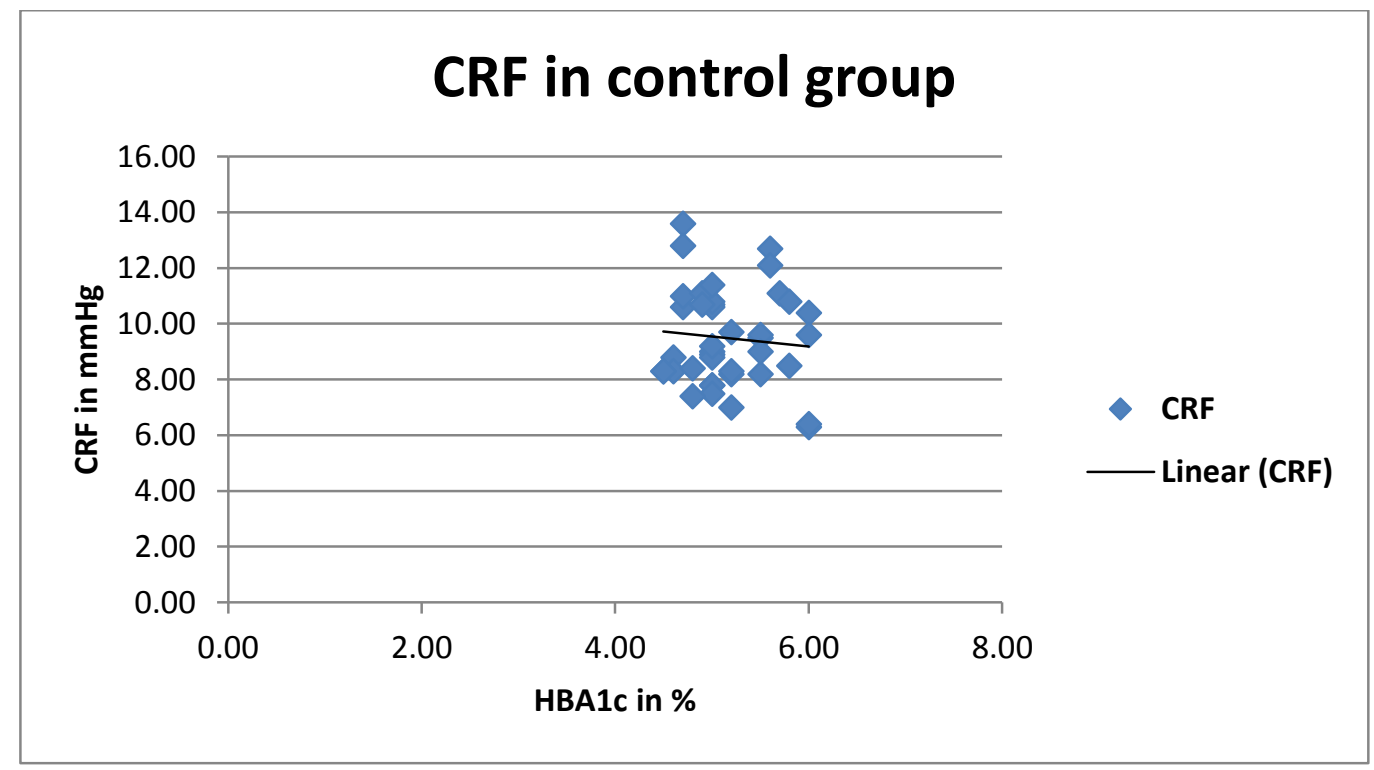

Figure 5: Scatter plot showing very weak negative linear correlation between CRF and HBA1c in control group, ( $r$ value $=-0.092)$. 
When we did correlation between CRF and HBA1c in diabetic group (group B), it was found to be a moderate positive linear correlation, $(\boldsymbol{r}$ value $=\mathbf{0 . 3 5 3})(\boldsymbol{p}$ value $=\mathbf{0 . 0 2 5})$.

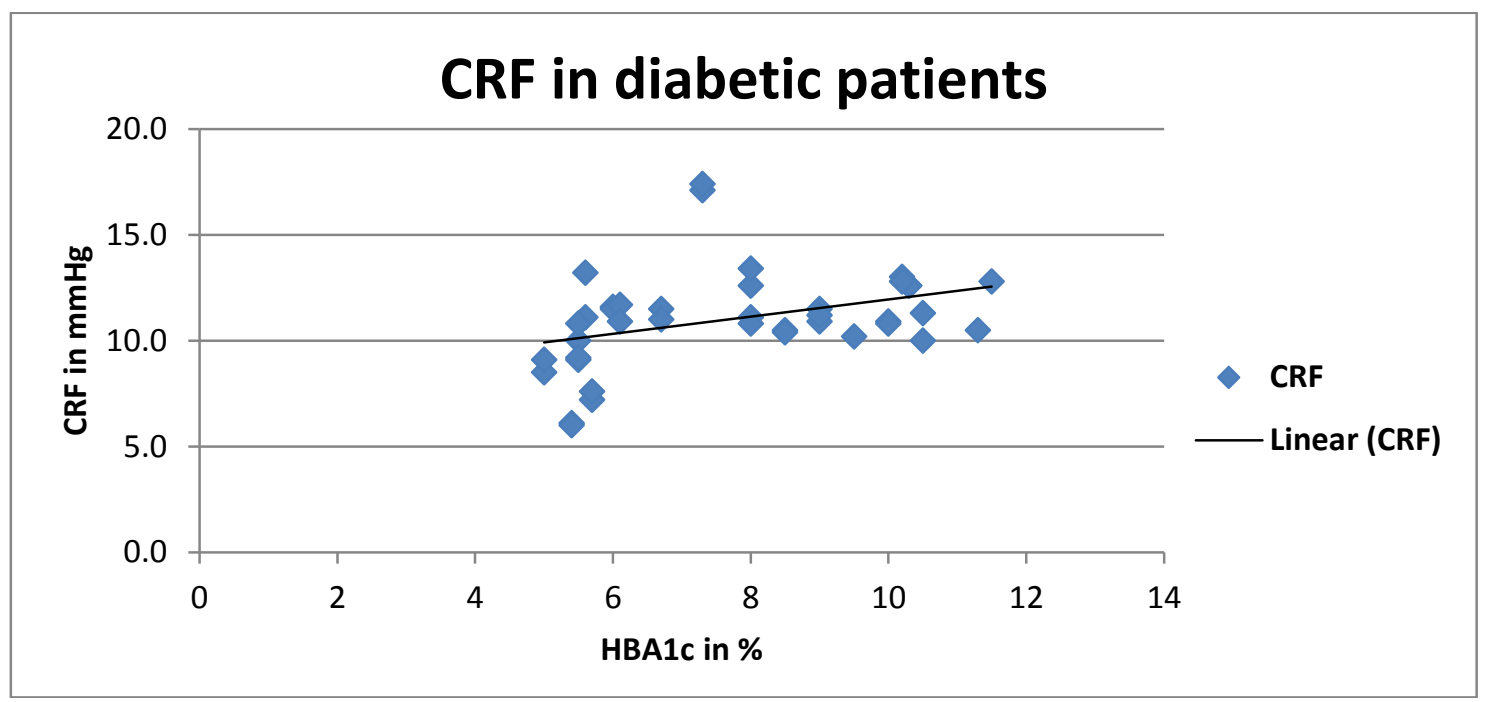

Figure 6: Scatter plot showing moderate positive linear correlation between CRF and HBA1 in diabetic patients, $(\boldsymbol{r}$ value $=\mathbf{0 . 3 5 3})$

\section{Discussion}

In our study, mean $\mathrm{CH}$ in control group (group A) was $9.8 \pm 1.3 \mathrm{~mm} \mathrm{Hg}$ in comparison to mean $\mathrm{CH}$ in diabetic group (group B) which was $11.9 \pm 1.4 \mathrm{~mm} \mathrm{Hg}$, which was statistically significantly higher in diabetic patients when compared to control group, $(P$ value $=0 .<001)$.

Our results could be explained by increased glucose in diabetes that acts as a collagen crosslinking agent with the help of advanced glycation end products (AGEs). AGEs accumulate in collagen proteins, resulting in the formation of covalent cross-linking bonds and gradual corneal stiffening.

Kotecha et al $^{(7)}$ mentioned in their results that $\mathrm{CH}$ is slightly higher in diabetic eyes with $P$ value $=0.21$.

On the contrary, Sahin et al. ${ }^{(8)}$ reported that mean $\mathrm{CH}$ in control group was $10.41 \pm 1.66 \mathrm{~mm}$ $\mathrm{Hg}$ in comparison to mean $\mathrm{CH}$ in diabetic group which was $9.51 \pm 1.82 \mathrm{~mm} \mathrm{Hg}$. They also reported that mean $\mathrm{CH}$ was significantly lower in diabetic patients when compared to the control group, $(P$ value $=0.0001)$. They explained the decrease in $\mathrm{CH}$ by an alteration in the collagenous components due to collagen cross-linking suggesting that the dampening effects of the cornea decrease due to diabetes and were induced to increase during the cross-linking of collagen fibrils.

Meanwhile, Goldich et al. ${ }^{(9)}$ disagreed with our results as they noted that there was no statistically significant difference between the control and diabetic groups regarding $\mathrm{CH}$ values. They didn't note any explanations.

Scheler et al. (10) also disagreed with our results as he showed that there were no differences detected between healthy controls and patients with well-controlled diabetes as regard to $\mathrm{CH}$.

In present study, the mean CRF value of control group (group A) was $9.41 \pm 1.5 \mathrm{~mm} \mathrm{Hg}$ in comparison to $12.4 \pm 1.7 \mathrm{~mm} \mathrm{Hg}$ in diabetic group (group B) and the difference between both groups was significantly higher in diabetic patients, $(P$ value $=0.001)$.

Cankaya et al. ${ }^{(11)}$ also showed similar results to ours as they reported that mean CRF in control 
group was $10.56 \pm 0.5 \mathrm{~mm} \mathrm{Hg}$ in comparison to $11.58 \pm 0.6 \mathrm{~mm} \mathrm{Hg}$ in diabetic group. the difference between control and diabetic groups was statistically significantly higher ( $P$ value $<0.01)$ but they didn't explain this finding.

\section{Conclusion}

the corneal biomechanics in diabetic group are significantly higher compared with those of the control group as the mean $\mathrm{CH}$ is $9.8 \pm 1.3 \mathrm{mmHg}$ in the control group (group A) and is $11.9 \pm 1.4 \mathrm{mmHg}$ in the diabetic group (group B). The difference in $\mathrm{CH}$ between the two groups is statistically highly significant, $(\boldsymbol{p}$ value $=$ $<0.100)$. Meanwhile the mean CRF is $9.41 \pm 1.5$ $\mathrm{mmHg}$ in the control group (group A) and is $12.4 \pm 1.7 \mathrm{mmHg}$ in the diabetic group (group B) and the difference in CRF between the two groups is statistically highly significant, ( $\boldsymbol{p}$ value $=0.001)$. In the control group, there is no correlation between $\mathrm{CH}$ and the average level of HBA1c, $(\boldsymbol{r}$ value $=0.005)(\boldsymbol{p}$ value $=0.974)$. However, there is a weak positive linear correlation between $\mathrm{CH}$ and the average level of HBA1C in the diabetic patients, $(\boldsymbol{r}$ value $=0.129)$ ( $\boldsymbol{p}$ value $=0.427$ ). There is a very weak negative linear correlation between $\mathrm{CRF}$ and the average level of HBA1c in the control group, $(\boldsymbol{r}$ value $=$ $0.092)(\boldsymbol{p}$ value $=0.570)$. However, the correlation between it and HBA1c in diabetic group is a moderate positive linear correlation, $(\boldsymbol{r}$ value $=0.353)(\boldsymbol{p}$ value $=0.141)$.

\section{References}

1. Nyquist GW (1968): Rheology of the cornea: experimental techniques and results. Experimental eye research, 7(2):183-188.

2. Woo SL, Kobayashi AS, Lawrence C, Schlegel WA (1972): Mathematical model of the corneo-scleral shell as applied to intraocular pressure-volume relations and applanation tonometry. Annals of biomedical engineering, 1(1):87-98.

3. Touboul D, Roberts C, Kerautret J, Garra C, Maurice-Tison S, Saubusse E, Colin J (2008): Correlations between corneal hysteresis, intraocular pressure, and corneal central pachymetry. Journal of cataract and refractive surgery, 34(4):616-622.

4. Luce D https://iovs.arvojournals.org/

(2003):

5. Shah $S$, Laiquzzaman M, Bhojwani R, Mantry S, Cunliffe I (2007) : Assessment of the biomechanical properties of the cornea with the ocular response analyzer in normal and keratoconic eyes. Investigative ophthalmology \& visual science, 48(7):3026-3031.

6. Gekka M, Miyata K, Nagai Y (2004); Corneal epithelial barrier function in diabetic patients. Cornea, 23:35-37.

7. Kotecha A, Oddone F, Sinapis C, Elsheikh A, Sinapis D, Sinapis A et al. (2010): Corneal biomechanical characteristics in patients with diabetes mellitus. J Cataract Refract Surg., 36(11):1822-1828.

8. Sahin A, Bayer A, Özge G, Mumcuoglu T (2009): Corneal biomechanical changes in diabetes mellitus and their influence on intraocular pressure measurements. Invest. Ophthalmol. Vis. Sci., 50: $4597-$ 5604.

9. Goldich Y, Barkana Y, Gerber Y, Rasko A, Morad Y, Hasrstein M, Avni I, Zadok D. (2009): Effect of diabetes mellitus on biomechanical parameters of the cornea. J. Cataract Refract. Surg., 35:715-19.

10. Scheler E, Andreas G (2012) : Effect of diabetes mellitus on corneal biomechanics and measurement of intraocular pressure. Acta Ophthalmologica,. 90(6): e447-e451.

11. Cankaya E, Ercan G, Selim D et al. (2012): Corneal biomechanical characteristics, intraocular pressure and central corneal thickness in patients with type 2 diabetes mellitus. Journal of Clinical Medicine and Research, 4 (6):79-83. 